\title{
MATURAÇÃO FISIOLÓGICA DAS SEMENTES DAS CULTIVARES BR 007 A E BR 007 B DE SORGO (SORGHUM BICOLOR L. MOENCH) ${ }^{1}$
}

\author{
CLEVERSON SILVEIRA BORBA, RAMIRO VILELA DE ANDRADE, \\ JOÄO TITO DE AZEVEDO E ANTONIO CARLOS DE OLIVEIRA²
}

\begin{abstract}
RESUMO - Sementes das cultivares de sorgo BR 007 A e BR 007 B, colhidas diariamente a partir de 21 dias após a floração foram analisadas quanto ao teor de umidade, acúmulo de matéria seca, germinação e vigor. O experimento foi instalado em 1990, no Centro Nacional de Pesquisa de Milho e Sorgo da EMBRAPA, em Sete Lagoas, MG. Dos resultados obtidos, pôde-se concluir que a melhor época para a colheita de sementes de alta qualidade, para as cultivares BR 007 A e BR 007 B, está em torno de 33 dias após início do florescimento.
\end{abstract}

Termos para indexação: umidade, matéria seca, germinação, vigor, sorgo.

\section{PHYSIOLOGICAL MATURATION OF BR 007 A AND BR 007 B SEEDS OF SORGHUM (SORGHUM BICOLOR L. MOENCH)}

\begin{abstract}
Sorghum seeds of cultivars BR 007 A and BR 007 B, harvested daily since 21 days from flowering were analysed to moisture content, dry matter accumulation, germination and vigor. The experiment was carried out in 1990 at the "National Maize and Sorghum Research Center" of EMBRAPA in Sete Lagoas, state of Minas Gerais. The results showed was that the best time to harvest seeds of high quality was around 33 days after flowering for both cultivars.

Index terms: moisture, dry matter, germination, vigor, sorghum.
\end{abstract}

\section{INTRODUÇÃO}

O conhecimento da melhor época de colheita é imprescindível para a produção de sementes de alta qualidade. Sua determinação baseia-se geralmente em apenas dois parâmetros: 0 teor de umidade das sementes e o aspecto das plantas. Entretanto esses parâmetros nem sempre são suficientes para indicar o momento mais favorável. Assim um maior conhecimento da maturação fisiológica das sementes torna-se necessário.

Andrade \& Oliveira (1988) estudando a maturação fisiológica do colmo e da semente de sorgo sacarino verificaram que os maiores índices de germinação e vigor, foram obtidos quando as sementes estavam com a umidade em torno de $30 \%$, correspondendo ao intervalo de 35 a 44 após o início da floração.

Estudando o efeito da colheita em diferentes estádios de maturação sobre

\footnotetext{
1 Aceito para publicação em 28.09.92.

2 Pesquisadores do Centro Nacional de Pesquisa de Milho e Sorgo/EMBRAPA. Caixa Postal 151 - CEP 35700 Sete Lagoas, MG.
}

a qualidade fisiológica das sementes de cinco cultivares de sorgo granífero, Costa et al. (1990) concluiram que a melhor época de colheita está em torno de 30 dias após a floração, para as cultivares IPA 86002502, IPA 73001011, IPA 8602527 e IPA 8602528 e aos 44 dias para a cultivar IPA 7300201.

Sales (1978) em um trabalho sobre maturação de sementes do sorgo NK-233, encontrou que o máximo de germinação foi observado para as sementes colhidas aos 29 dias após a floração. O máximo de vigor foi obtido para as sementes colhidas aos 45 dias após a floração e o máximo de peso seco e volume das sementes foram atingidos aos 41 dias. Considerando-se o peso seco, volume, germinação e vigor, o ponto de maturação fisiológica das sementes ocorreu aproximadamente aos 45 dias após a floração e nesse ponto as sementes apresentaram um teor de umidade em torno de $30 \%$.

Kersting et al. (1961) estudando o desenvolvimento da cariopse de sorgo Kafir-60 em Kansas nos EUA, verificou que a máxima acumulação de matéria seca ocorreu aos 45 dias após a floração com $23 \%$ de umidade no ano agrícola de 1958 e aos 33 dias, com $30 \%$ de umidade no ano de 1959. A máxima germinação foi encontrada aos 38 e 33 dias após a floração nos anos de 1958 e 1959 respectivamente.

O presente trabalho tem como objetivo estudar a maturação fisiológica das sementes de sorgo BR $007 \mathrm{~A}$ e BR $007 \mathrm{~B}$, tomando como base os parâmetros teor de umidade, materia seca, germinação e vigor, para a determinação da melhor época para a colheita de sementes com mais alta qualidade.

\section{MATERIAL E MÉTODOS}

O experimento foi conduzido no Centro Nacional de Pesquisa de Milho e Sorgo da EMBRAPA, em Sete Lagoas, MG, cujas coordenadas geográficas são $19^{\circ} 28^{\prime}$ de latitude $\mathrm{S}$ e $44^{\circ} 15^{\prime} 08^{\prime \prime}$ de longitude $\mathrm{W}$.

As sementes foram obtidas de uma lavoura de produção semeada em 07.11.1990, formada com a intercalação de quatro fileiras da cultivar $\mathrm{BR} 007 \mathrm{~A}$ com macho-esterilidade e duas fileiras com a cultivar BR 007 B como polinizadora. A floração foi considerada quando $50 \%$ das plantas apresentaram 
as flores abertas em 15.01.91.

Diariamente a partir de 21 dias após a floração, vinte panículas de cada cultivar foram colhidas ao acaso até 22.03.91. Imediatamente após cada colheita, as panículas foram debulhadas manualmente e retirou-se uma amostra de sementes para a determinação do teor de umidade, pelo "método da estufa", conforme prescrevem as Regras para Análise de Sementes - RAS (Brasil, 1980). As sementes restantes foram colocadas para secar à sombra e após atingirem umidade em torno de $13 \%$, foram acondicionadas em sacos de papel e guardadas em câmara fria e seca para posteriores análises.

O teor de matéria seca foi determinado com a secagem de 400 sementes de cada amostra, em estufa a $105^{\circ} \mathrm{C}$ por 24 horas e a seguir foram pesadas e os resultados expressos em $\mathrm{mg} / \mathrm{semen}$ te.

A germinação das sementes foi determinada pelo método prescrito pelas RAS (Brasil, 1980), utilizando-se 50 sementes por repetição.

$O$ vigor das sementes foi determinado pelo teste de Envelhecimento acelerado, sendo as sementes colocadas em câmara tipo $\mathrm{BOD}$ a $42^{\circ} \mathrm{C}$ por 120 horas. A seguir foram colocadas para germinar conforme teste padrão de germinação prescrito pelas RAS (Brasil, 1980).

Adotou-se o delineamento experimental inteiramente casualizado com 20 repetições, sendo cada repetição representada por uma panícula. Os dados obtidos foram ajustados utilizando-se modelos de regressão exponenciais e quadráticos. Para o caso específico de germinação e vigor ajustaram-se duas retas. A primeira corresponde ao período compreendido entre o início de tomada dos dados (21 dias após a floração) até o ponto máximo observado de germinação e vigor (33 dias após a floração). A segunda inicia-se no ponto a partir do qual houve a mudança na tendência dos dados (34 dia após a floração), prolongando-se até o $66^{\circ}$ dia após a floração. As retas foram ajustadas tomando-se como base o seguinte modelo de regressão (Hoffman
\& Vieira (1983):

$$
\mathrm{Y}=\alpha+\beta 1 \mathrm{~V} 1+\beta 2 \mathrm{~V} 2+\mathrm{YZ}+\mu,
$$

onde V1 e V2 são variáveis artificiais que representam o passar do tempo, antes de ser efetuada a 33a observação e a partir da 34a observação, respectivamente; e $Z$ é uma variável binária que assume valor zero para as 13 primeiras observações (do 21ㅇ ao $33^{\circ}$ dia após a floração) e valor um para as 32 últimas observações (do $34^{\circ}$ ao $66^{\circ}$ dia após a floração). Os demais parâmetros são os usuais dos modelos de regressão linear simples.

\section{RESULTADOS E DISCUSSÃO}

Conforme pode ser observado nas Figuras 1 e 2, o teor de umidade das sementes que aos 21 dias após a floração estava em torno de $63 \%$ e $66 \%$, decresceu exponencialmente até aproximadamente $13 \%$ e $14 \%$, aos 66 dias, para cultivares BR 007 A e BR $007 \mathrm{~B}$, respectivamente. A umidade para níveis de colheita mecânica $(<20 \%)$ somente ocorreu a partir de 54 dias após a floração.

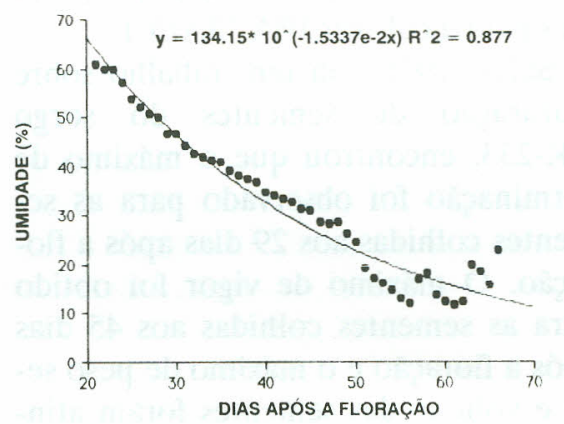

FIG. 1. Umidade das sementes da cultivar BR 007 A de sorgo, colhidas em diversas épocas. CNPMS, Sete Lagoas, MG, 1991.

A germinação das sementes no período compreendido entre 21 e 66 dias após a floração, para as cultivares BR 007 A e BR 007 B, pode ser observado nas Figuras 3 e 4 . Inicialmente ocorreu um incremento nos percentuais de germinação, a cada dia após a floração, de 6,8\% e 7,6\%, para as cultivares $\mathrm{BR} 007 \mathrm{~A}$ e $\mathrm{BR} 007 \mathrm{~B}$, respectivamente. Ambas as cultivares atingiram percentual máximo de germinação aos 33 dias após o início da floração. Isso corresponde, a um teor de umidade das sementes, de aproximadamente $42 \%$ e $43 \%$ (Figuras 1 e 2 ).

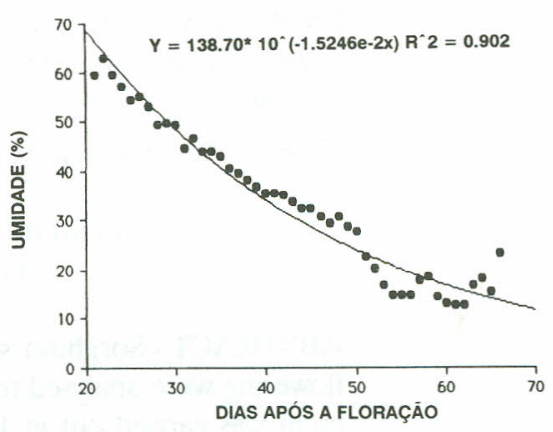

FIG. 2. Umidade das sementes da cultivar BR 007 B de sorgo colhidas em diversas épocas. CNPMS, Sete Lagoas, MG. 1991.

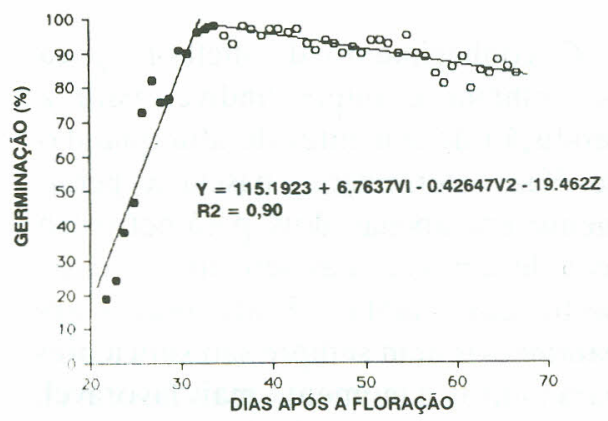

FIG. 3. Germinação das sementes da cultivar BR 007 A de sorgo colhidas em diversas épocas. CNPMS, Sete Lagoas, MG. 1991.

V1 = representa o passar do tempo antes de $34^{\circ}$ dia após a floração. $\mathbf{V} \mathbf{2}=$ representa o passar do tempo a partir do $34^{\circ}$ dia após a floração. $\mathbf{Z}=$ variável binária.

A partir do 349 dia, no entanto, houve uma mudança no comportamento da germinação e os percentuais apresentaram-se decrescentes a taxas diárias, de aproximadamente $0,43 \%$ e $0,51 \%$ para as cultivares BR $007 \mathrm{~A}$ e $\mathrm{BR} 007 \mathrm{~B}$, respectivamente. O decréscimo na percentagem de germinação, 
que chegou a $82 \%$ e $81 \%$, para as cultivares $B R 007$ A e BR $007 \mathrm{~B}$, respectivamente, ocorrido aos 66 dias após o início da floração, foi provavelmente devido à deterioração das sementes causada pelas chuvas que ocorreram no período (Figura 9).

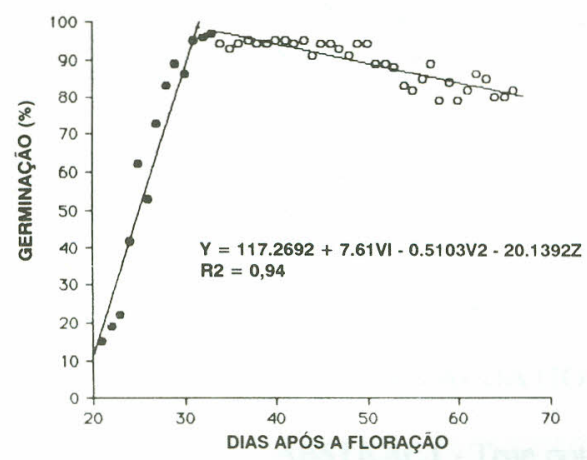

FIG. 4. Germinação das sementes da cultivar BR 007 B de sorgo colhidas em diversas épocas. CNPMS, Sete Lagoas, MG. 1991.

V1 $=$ representa o passar do tempo antes de 34\% dia após a floração. V2 $=$ representa 0 passar do tempo a partir do $34^{\circ}$ dia após a floração. $\mathbf{Z}=$ variável binária.

$\mathrm{O}$ período em que foi atingido o máximo nível de germinação coincidiu com os resultados encontrados por Kersting et al. (1961) 33 dias, no ano agrícola de 1959. Entretanto foi diferente aos encontrados por Kersting et al. (1961), 38 dias, no ano agrícola de 1958 e pelo encontrado por Sales (1978) 29 dias. Essas diferenças de resultados, provavelmente deveram-se a adversidades climáticas ocorridas durante o período de maturação.

Observa-se pelas Figuras 5 e 6 que os valores máximos de matéria seca das sementes, $26 \mathrm{mg} / \mathrm{semente}$ e $21 \mathrm{mg} / \mathrm{se}$ mente, ocorreram aos 52 dias após o início da floração, o que corresponde a um vigor em torno de $88 \%$ e $87 \%$ para as cultivares $\mathrm{BR} 007 \mathrm{~A}$ e $\mathrm{BR} 007 \mathrm{~B}$, respectivamente. Estes resultados diferem dos encontrados por Sales (1978) e Kersting et al. (1961), 41 e 45 dias respectivamente, provavelmente devido ao uso de cultivares, locais e épocas de semeaduras diferentes.

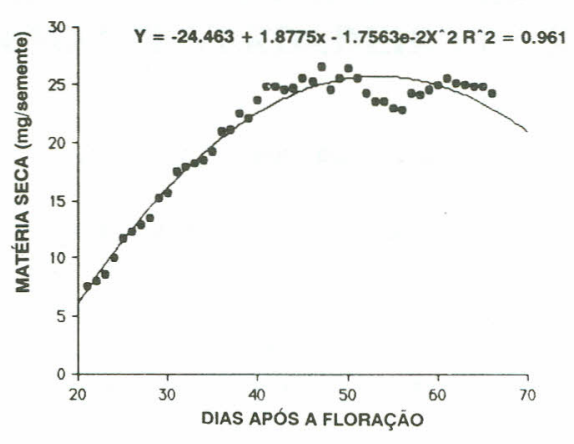

FIG. 5. Matéria seca das sementes da cultivar BR 007 A de sorgo, colhidas em diversas épocas. CNPMS, Sete Lagoas, MG. 1991.

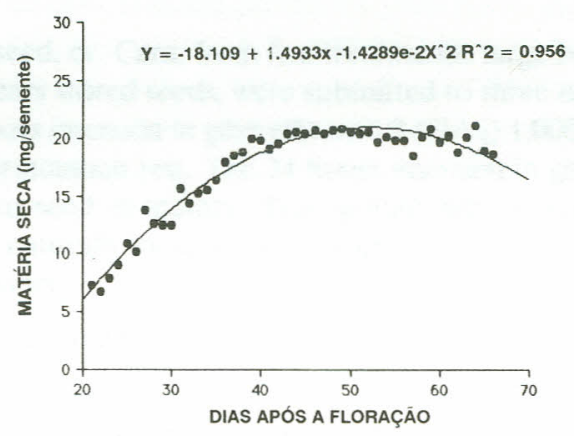

FIG. 6. Matéria seca das sementes da cultivar BR 007 B de sorgo colhidas em diversas épocas. CNPMS, Sete Lagoas, MG. 1991.

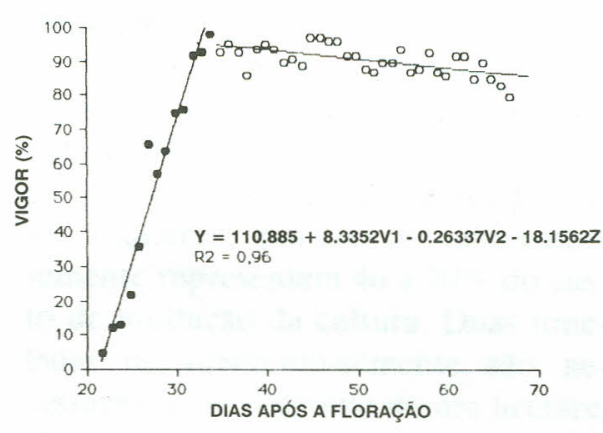

FIG. 7. Vigor das sementes da cultivar BR 007 A de sorgo colhidas em diversas épocas. CNPMS, Sete Lagoas, MG. 1991.

V1 = representa o passar do tempo antes do 34 dia após a floração. $\mathbf{V} \mathbf{2}=$ representa o passar do tempo a partir do $34^{\circ}$ dia após a floração. $Z=$ variável binária.
$\mathrm{O}$ vigor das sementes teve comportamento semelhante à germinação (Figuras 7 e 8). Iniciando com percentagens abaixo de $10 \%$, atingindo níveis máximos aos 33 dias após o início da floração, para ambas as cultivares em estudo. Estes resultados diferiram dos demais citados na revisão de literatura provavelmente devido a diferenças climáticas ocorridas no período.

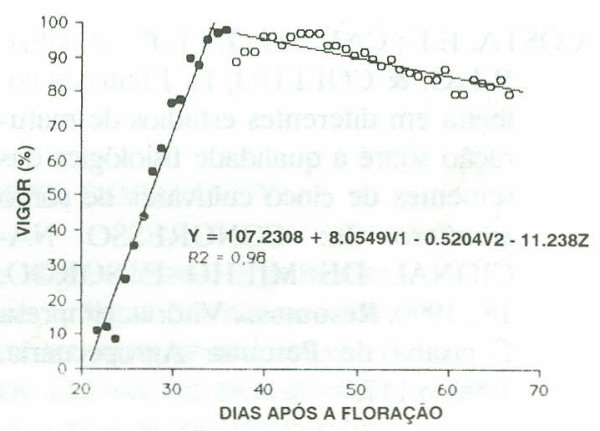

FIG. 8. Vigor das sementes da cultivar BR $007 \mathrm{~B}$ de sorgo colhidas em diversas épocas. CNPMS, Sete Lagoas, MG. 1991.

V1 = representa o passar do tempo antes do $34^{\circ}$ dia após a floração.

V2 $=$ representa o passar do tempo a partir do $34^{\circ}$ dia após a floração. $\mathbf{Z}=$ variável binária.

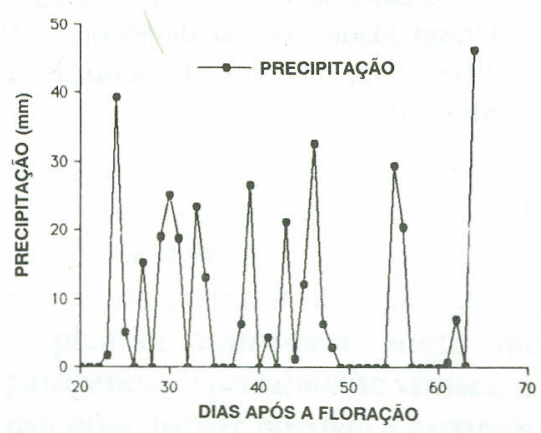

FIG. 9. Precipitação $(\mathrm{mm})$ ocorrida desde 21 até 66 dias após a floração (05.02.91 a 22.03.91) do sorgo plantado em 07.11.90. CNPMS, Sete Lagoas, MG. 1991.

\section{CONCLUSÕES}

A melhor época para a colheita de sementes de alta qualidade, para as cultivares BR 007 A e BR 007 B, está em 
torno de 33 dias após início do florescimento.

\section{REFERÊNCIAS}

ANDRADE, R.V. \& OLIVEIRA, A.C. Maturação fisiológica do colmo e da semente de sorgo sacarino. R. Bras. Sem., Brasîlia, 10(3):19-31, 1988.

BRASIL. Ministério da Agricultura. Regras para Análise de Sementes. Brasilia, MA-SNAD-LANARV, 1980. 188p.

COSTA, E.F.; CAMPELO, J.E.E.; SOUSA, R.L.G. \& COELHO, H. Efeito da colheita em diferentes estádios de maturação sobre a qualidade fisiológica das sementes de cinco cultivares de sorgo granífero. In: CONGRESSO NACIONAL DE MILHO E SORGO, 18., 1990. Resumos... Vitória. Empresa Capixaba de Pesquisa Agropecuária. 1990, p.117.

HOFFMANN, R. \& VIEIRA, S. Análise de Regressão. Uma introdução à econometria. São Paulo, Ed. Hucitec, 1983. $379 \mathrm{p}$.

KERSTING, J.F.; STICKLER, F.C. \& PAULI, A.W. Grain sorghum caryopsis development. 1. Changes in dry weight, moisture percentage, and viability. Agron. J., 53:36-37, 1961.

SALES, I.C. Maturação de sementes de sorgo (Sorghum bicolor (L.) Moench). Universidade Federal de Pelotas, RS. 1978. 94p. (UFPel. Dissertação de Mestrado). 